\title{
VirtualBusinessTeams for Professional Development and Team Learning
}

\author{
W. Van Petegem, P. Sloep, J. Gerrissen, D. Jansen, and R. Schuwer \\ Open University of the Netherlands, P.O. Box 2960, 6401 DL Heerlen (The Netherlands), \\ Tel: +31-45-576.21.43, fax: +31-45-576.21.15, e-mail: wim.vanpetegem@ou.nl
}

Key words: VirtualBusinessTeams, team learning, collaborative work, knowledge management, competence-based learning

\begin{abstract}
The Open University of the Netherlands recently started an innovative research project called the Virtual Company, featuring "VirtualBusinessTeams" (VBTs) as its key components. A VBT is both an organization-for-learning and a learning organization. Four principal deployment modes are distinguished: 1) business-task-paced learning, 2) learning at work, 3) organizational prototyping, and 4) knowledge management towards competence growth. A typical VBT workbench provides tools to support collaborative work in a networked environment, tools for assessment and guidance, and tools for knowledge management. Although the various kinds of VBTs differ slightly from each other, a generic object model is derived that represents the typical infrastructure. The first operational implementation of a VBT was named "Incompany Environmental Consult." Based on the evaluation results of this alpha-run, we are now fine-tuning and further elaborating the concept of VBTs in two beta-runs, which are undertaken together with Information and Communications Technology (ICT) companies.
\end{abstract}

\section{INTRODUCTION}

It hardly is an overstatement to say that it is education's main purpose to supply the labor market with a steady supply of well-trained youngsters eager to play their part in that market. Technological innovations have long been the engine that has powered the economic development of western corrected. The Erratum to this chapter is available at DOI: 10.1007/978-0-387-35502-3_19 
society. Interestingly, the pace of technological innovation seems to have been increasing for quite a while. Whatever the intricacies of this process of change, it cannot but give rise to profound and continuously changing demands upon employees. More specifically, we contend that the classical ideals of erudition and scholarship, with their emphasis on knowledge of facts, had better be replaced by an educational system that supports the acquisition of skills or competencies.

The change of pace of our modern society also affects the kind of pedagogy to be used. In order for competence learning to be effective, students had better gather knowledge, and the skills and attitudes to apply it adequately, from their interaction with the physical and social environment, as constructivist pedagogy holds. According to this view, learning-seen broadly-is an individual experience that depends highly on the characteristics of the environment, the learning activities, and the goals of the learner. Learning is considered to result from an active process of knowledge construction within the environment rather than a passive process of knowledge reproduction about the environment. The validity of new knowledge is continuously tested against new experiences and understandings of other individuals. For the educator, constructivism implies not only that the environment should be rich and sufficiently complex to provide students with a wealth of api experiences, but also that it should actively support collaboration with others. Ultimately, knowledge acquisition is a process of social construcion, reflecting social transactions and agreements. Therefore, from a constructivist vantage point, a learning environment that in relevant aspects resembles real life best supports the kind of learning that is to serve student functioning in real life. After all, such a learning environment exhibits a natural complexity that forces its inhabitants to develop tacit and implicit know/ledge. By setting authentic prohlems for the learner it generates in rinsic motivation. It resembles the

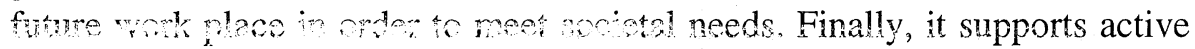

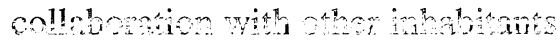

Therefcre, aning at a tuly noverive educational approach involves a number of aspecto efiecting these sccietal trends:

$\therefore$. he growing heen ivi nexivie, failor-made ediucational programs that address maividual expectaiions and ambitions,

2. the need to integrate learning and working environments,

3. the need for competence-based learning programs,

4. the growing interest in distance education as an educational concept and delivery method,

5. the growing interest in constructivist pedagogy,

6. the advent new information and communication technologies with promising pomials for education. 
To address these trends the Open University of the Netherlands recently started an innovative research project called the Virtual Company, featuring "VirtualBusinessTeams" (VBTs) as its key components [Wes98a, Schu98, VPet99].

The present paper first explains the VBT concept and its main characteristics. It then elaborates on four principal deployment modes. Subsequently, the paper outlines the basic infrastructure, including generic instruments to realize the necessary functionality. The first implementations of VBTs are described together with some research results. The paper concludes with some remarks on work in progress.

\section{DEFINITION AND CONCEPT}

The name VirtualBusinessTeam is partly inspired by the concept of Virtual Teams as described in [Lip97, pp. 6 - 7]:

Virtual teams are live. They are most definitely teams, not electronic representations of the real thing. They are going digital, using the Internet and Intranets. Unlike conventional teams, a virtual team works across space, time, and organizational boundaries with links strengthened by webs of communication technologies.

We call them VirtualBusinessTeams since such a team really operates in the context of either a standing or a simulated business organization.

A VirtualBusinessTeam (VBT) is both an organization-for-learning, and a learning organization. The VBT member is a tele-worker in a networked enterprise, a cluster of personal desks or workbenches equipped to support various forms of collaborative work. The network might be the Internet, a real company's Intranet, or extranet.

The concept of a VBT does not exclude time-and-place coincidence (colocation) of team members. Rather, it results from an emphasis on asynchronous work forms that are enabled by a network-like connectivity between the team members and between their individual workstations. Organization of the work, the kind of work, business rules, and work objects and instruments are all typical for a specific class of businesses, industries, government agencies, consultant offices and/or a specific profession.

\section{PRINCIPAL DEPLOYMLNT MODES}

The VBTs really are teams of students or trainees who perform work assignments sit within a real-life project or within a section of a functional 
organization. Task commitments provoke the learning of new individual as well as team competencies. For the VBT members, the primary challenge is their work and the obligation to contribute to the team performance; learning results because the work ultimately is an embedded problem-solving venture.

Although these are the basic elements common to each kind of VBT, differences in detail do exist. At present, we distinguish four principal deployment modes of a VBT [Sloep99], as is illustrated by Figure 1.

The most basic VBT deployment mode might be labeled "Business-taskpaced Learning." Its primary aim is to immerse university students in demanding company tasks, as an early and timely exposure to their future professional practice. The need for functional elicitation and use of knowledge and skills when exposed to the "real" problems of a representative job highly motivates the students to engage actively in the management of appropriate knowledge sources.

In talking with Professional Development (PD) and Management Development (MD) officers, we quickly came to understand the great potential of a second deployment mode that we coined the phrase "Learning at Work." It differs in two ways from customary learning-on-the-job approaches to training. For one, it is not meant to prepare a trainee to perform satisfactorily in a particular job. Rather, it aims at preparing trainees for whatever function and task that require a certain competence. Second, "at Work" means that the trainee continues doing his or her standing job that is supposedly productive in the organizational context. The crux is that in doing so, he or she is exposed to new methods, tools, or problems that demand improvement or broadening of capabilities. Also, in contrast to traditional company-external courses or seminars, the Learning at Work approach eliminates much of the transfer-of-training problems, and avoids the hassles of having to make travel arrangements, of dealing with absence from home and work, of coping with agenda mismatches, etc. 


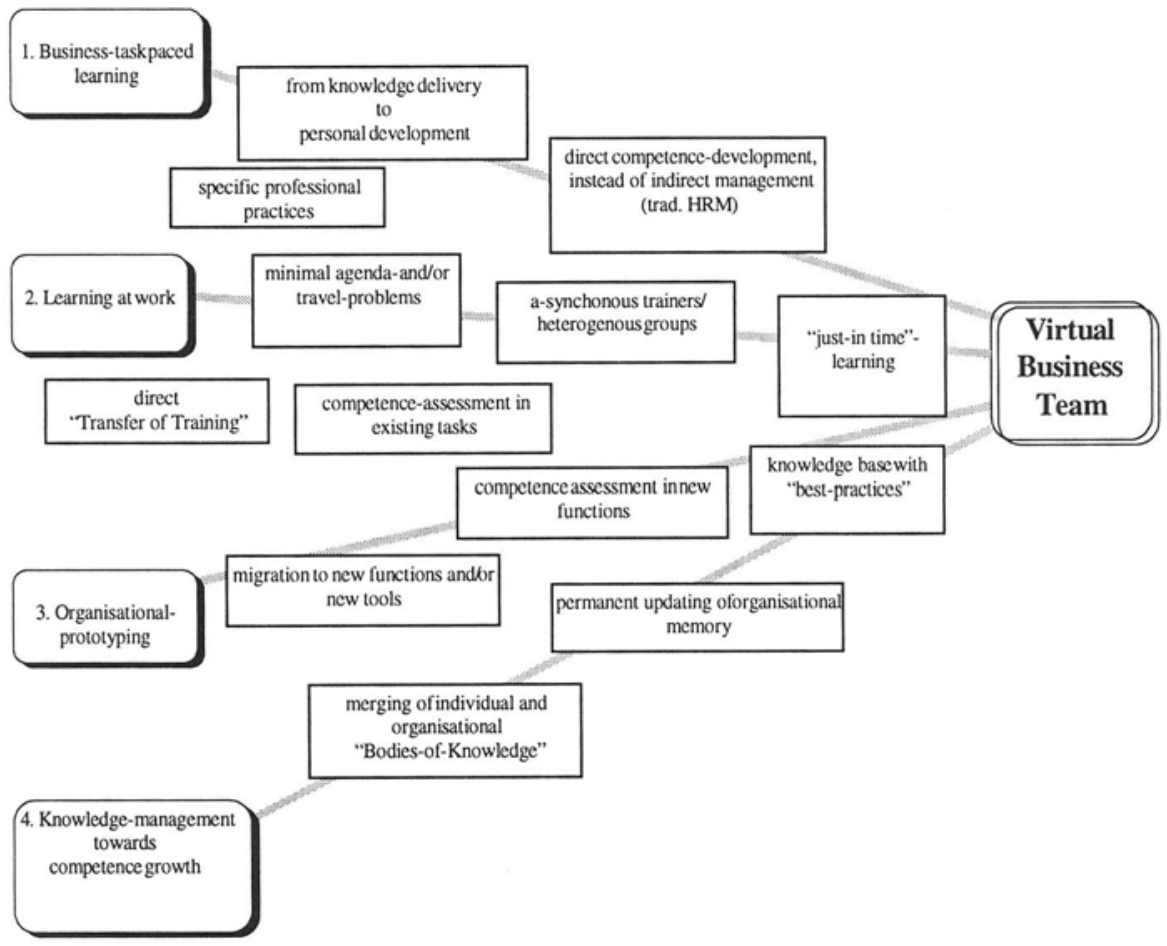

Figure 1 Principal Deployment Modes of VirtualBusinessTeams

The third mode, "Organizational Prototyping," focuses on the need for evaluating emerging options for organizational change, for instance, as a result of a Business-Process-Redesign (BPR) exercise. As a rule, the team that produced the new design of processes and concomitant organizational structures is optimistic about the ease of implementation and the absence of breakdown risks. Management, on the other, hand very much favors a realistic probing of the ins and outs before going ahead with massive transition and perhaps unwillingly passing the point of no return. Organizational Prototyping is a well-proven approach to testing the feasibility and sustainability of an organizational change. Building it on a VBT substrate allows for greatly added involvement, realism and "observability," as compared to the usual role- or game playing practices.

The fourth mode [Ger98], "Knowledge Management towards Competence Growth," stems from our appreciation of the fundamental difference between the learning mechanisms in VBTs, which are studentcentered, on the one hand, and mainstream teacher-oriented learning, on the other. Just-in-time learning stimuli from the formal body of knowledge, and the informal learning stimuli from team and organizational memory are 
merged, in the process leading to a desired task progress. In terms of knowledge management cycles, this is the part of the cycle that connects the initial knowledge acquisition with the result of personal knowledge processing. The next step, and the actual onset of a new cycle, starts with the consolidation of the improved or changed insights that result from the produced task result. VBT workstations may facilitate feeding these new insights to the formal and informal knowledge sources at hand; they foster the updating of inputs to have them available to future knowledge management cycles. Thus, there is a continuous upgrading of the VBT knowledge sources for personal, team and organizational memory purposes.

\section{TYPICAL INFRASTRUCTURE AND GENERIC INSTRUMENTS}

The Open University of the Netherlands has its historical roots in distance education, and, apart from a few corporate education programs that it runs, course delivery traditionally concerns students that progress individually through a curriculum at their own pace, place, and time.

When applying the VBT concept in a distance teaching context, the remote-study aspect and the inherent lack of synchronicity easily translate into the many computer and network requirements that have shaped the modern tele-workstations.

The top three components of Figure 2 indeed address the usual functionality classes that support tele-work: communication and coordination, (co-)work objects and tools and corporate knowledge, identity and rules. Complementary to the work support, we include functionality that,

1. helps trainees to overcome a deficiency that would cause task completion to stagnate, and (more so than with the average performance systems) to stimulate the establishment of competence growth: just-intime learning and coaching;

2. enables the identification, monitoring and assessment of this competence growth while the student or trainee and his or her team are at work:

competence modeling, monitoring and assessment.

Learning is abundant since it benefits from just-in-time comprehension (on a need-to-know basis) of task-relevant learning materials and coach guidance. It also benefits from the body of knowledge that resides, usually implicitly, in business rules, standard procedures, project documentation and work instrumentation that together constitute the organizational memory (corporate knowledge and identity). Before approaching the formal coaches or trainers, we often see trainees consult a team member (peer) with 
supposedly more or more easily accessible knowledge or experience on a given issue.

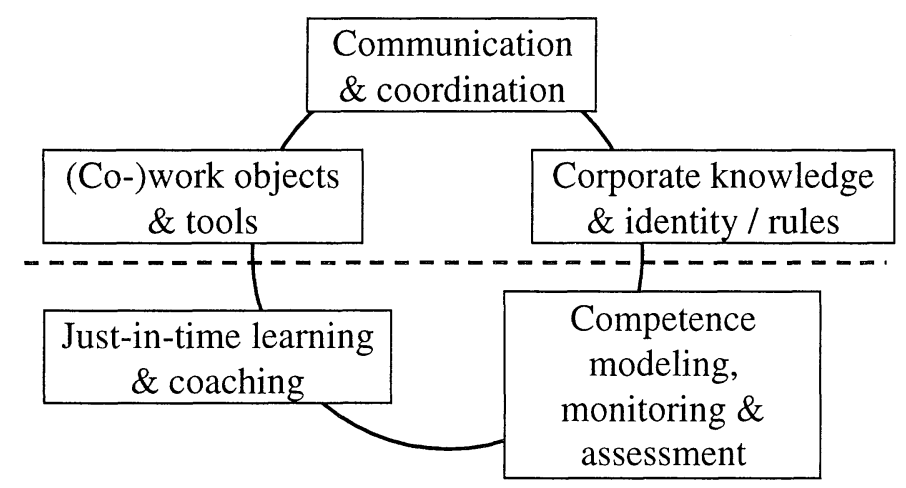

Figure 2 Typical VBT Workbench

It is clear from Figure 2 that the typical VBT workbench provides tools for different types of learning. The tools in the upper part support all types of learning through team activities (collaborative work in a networked environment). The tools in the lower part are typical learning tools based on assessment techniques. And the tools in the middle part along the dotted line are all related in some sense to knowledge management. Together they define the learning organization of a VBT as a strong organization-forlearning.

A generic object model representing the typical infrastructure of a VBT is given in Figure 3. 


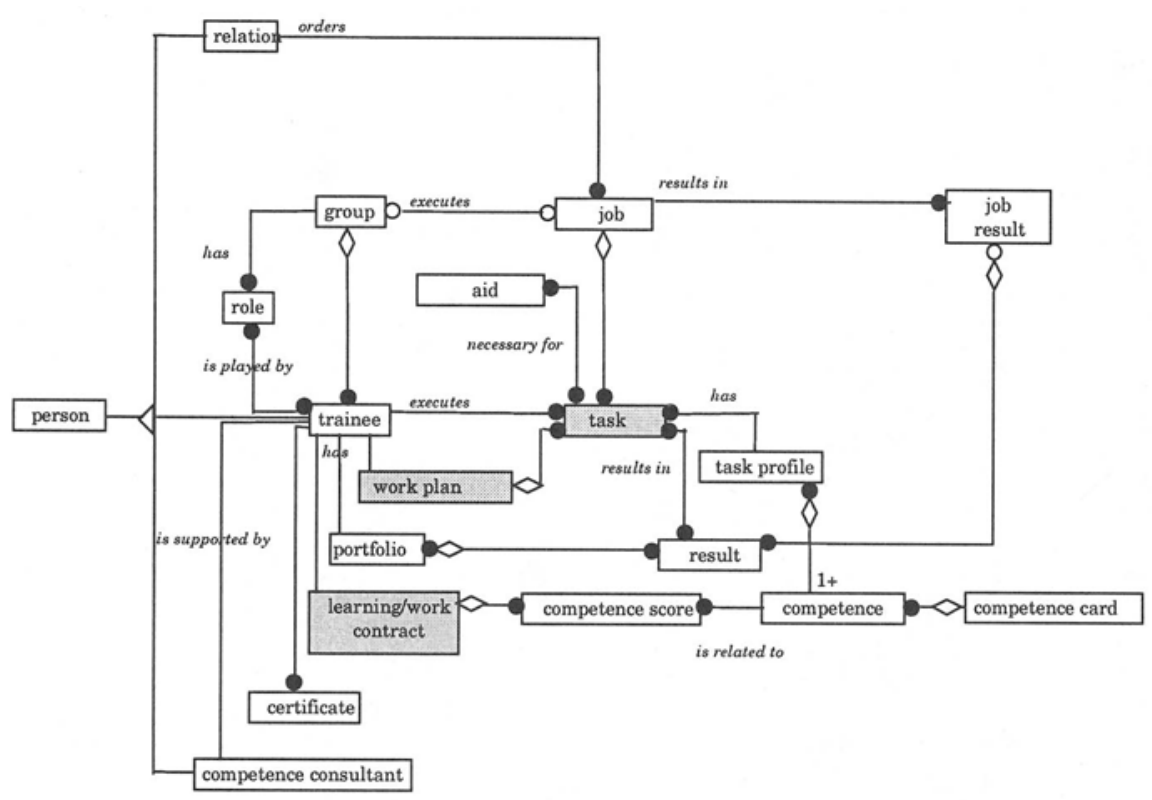

Figure 3 Object Model of a VBT

Figure 3 depicts a model that is a first attempt to describe formally which basic elements (objects) a VBT consists of and how they are related. Although the layout of Figure 3 might suggest otherwise, the competence card (lower right) is of pivotal importance. This becomes clear when we follow a few processes that follow each other in a typical VBT. All start with a real-life external "customer" (relation) who has a particular job that needs to be done and who is prepared to have it done by the VBT manned by trainees. The job is broken down into several tasks. For the completion of each one of these, particular competencies are needed, as described in the task profile. These competencies all need to be part of the agreed-upon competence card. Jobs that call upon competencies that are not part of the competence card will not be taken up.

Once tasks are thus characterised in terms of competencies, they then are allotted to the trainees. Matching up the task's competence profile with the trainee's competence profile does this. The trainee's competence profile, of course, is also a subset of the competence card. It is put together with the aid of teachers who play the role of competence counsellors. Together with the trainee, they draw up a trainee specific learning contract. Whenever all tasks in a job are finished (ending in the job result the external customer was so 
much interested in), the tasks completed are placed in the trainee's portfolio. During the entire process of working on different tasks within the context of a larger job, continuous assessments take place: self-assessments, assessments by peers, assessments by the competence counsellor. These assessments serve to update the competence scores in the individual trainee's learning contract.

\section{A PILOT}

The actual functioning of VBT work and learning environments will be presented in the form of short case descriptions of our implementations in corporate education and in curricular programs at institutions of higher education.

The first operational VirtualBusinessTeam was named "Incompany Environmental Consult." Its employees were 14 advanced students of the academic degree program in environmental sciences [Wes98b]. These students were experienced distance learners, but had only little experience with collaborative and computer-supported learning. A general manager, three competence counselors, and a helpdesk officer represented the educational staff. The experiment lasted about 12 weeks, with a total study load of about 120 hours. Students were equipped with a $300 \mathrm{MHz}$ Pentium PC in order to access the company's web-site, which contained all relevant information: the applied business model, a mission statement, a business philosophy, a range of products, an organizational structure (project organization), job descriptions, house rules, and the support structure, including an archive, references to relevant literature and links to available experts, instructional materials (fact sheets) and training facilities. 


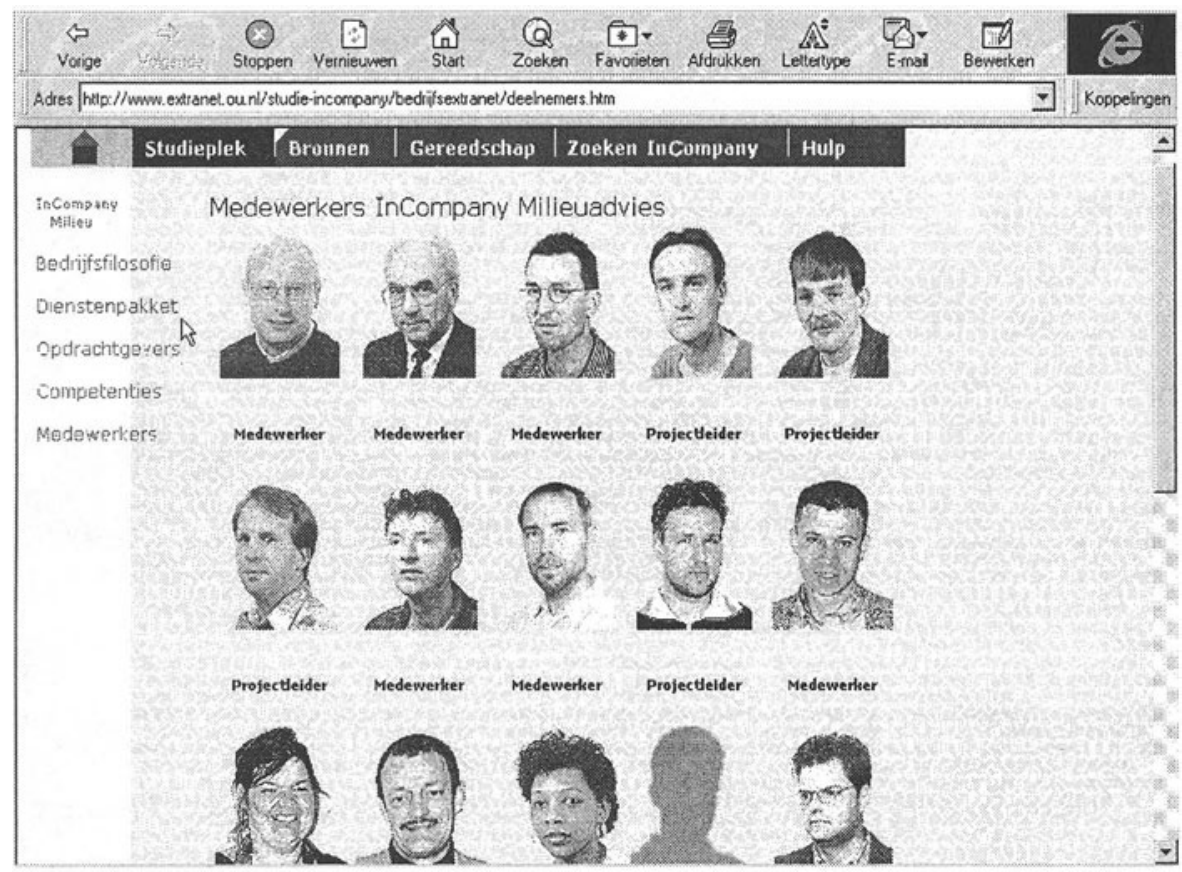

Figure 4 Presentation of Employees at the site of Incompany Environmental Consult

Communication software covered both synchronous and a-synchronous communication between fellow-employees. It was supplemented with BSCW (Basic Support for Cooperative Work) group-ware facilities. Students were assigned to one out of four project teams to work on authentic orders.

Evaluation of the pilot showed that the integration of learning and working in a VBT is highly motivating [Wes98b, OTEC98]. Students were greatly committed and appreciated the "thrill of reality." Collaborative learning via the network turned out to work quite well, despite a few initial technical problems. Indeed, learning and working appeared to be highly integrated, though sometimes the students gave high priority to customer interests at the expense of serving their own interests. At the start of the pilot, students complained about the overwhelming amount of information; it clearly hampered their functioning. In addition, students as well as educators reported some confusion about the various tasks and roles. It would be cynical to state that this confusion was a desired artifact of introducing reality. A better balance between chaos and structure should therefore be attempted. Furthermore, the tools for performance assessment and task assignment did not work as smoothly as they should in an operational Virtual Company. One might urge in excuse that the alpha-run be started out 
of the blue, lacking a common history, an existing culture, and common behavioral patterns.

Since the beginning of 1999 , we have been working on two beta-runs, together with two typical ICT (Information and Communications Technology) companies in the Netherlands, in order to further test and elaborate the VBT concept:

- In one experiment we try to transform an existing, complete ICT training for professionals without an adequate ICT background. A VBT learning organization is introduced, which we try to model as closely as possible after the business environment of the junior professionals. This means that all learning materials, communication, and coordination tools are at the disposal of the trainees just as in their daily business life. Meanwhile, they are functioning in a real-life job, working in collaboration with the other trainees on a specific assignment that is derived from a typical customer's job.

- In the second experiment, we explore the strengths of a VBT in Basic Design training for system developers. The training is now based on SDM-II to illustrate the business procedures followed in software design. Specifically, we introduce the tools and methods provided in VBTs for assessing competence growth as an alternative to the tight programming of the course due to the SDM-II technique.

Our first findings in both beta-runs are quite promising.

\section{CONCLUSION}

This paper presents the concept of VirtualBusinessTeams for professional development and team learning. A VBT is described as both an organization-for-learning and a learning organization with typical tools to support collaborative work in a networked environment, tools for assessment techniques and tools for knowledge management. Although the basic elements, described in a generic object model, are common to every kind of VBT, different principal deployment modes are distinguished. The research results of the first operational implementation of a VBT, named "Incompany Environmental Consult," were presented. Our experiences with this first implementation and with the present implementation projects have convinced us that the concept of learning and working in VirtualBusinessTeams is a very promising one indeed. It offers a new mode of learning that addresses in a unique and apparently successful way a number of issues present-day education has to face: it bridges the gap between learning and working, it can be easily adapted to changing demands, it is competence based, it allows for student interaction at a 
distance, it supports meaningful forms of assessment, and, last but not least, students like it very much!

\section{ACKNOWLEDGEMENT}

The VirtualBusinessTeam project is a collaboration between the Science and Technology Department and the Educational Technology Department of the Open University of the Netherlands. It is very much a team effort, which never could have come to fruition without the help of the other team members: Jo Boon, Jan van Bruggen, Dieuwke de Haan, Karel Kreijns, Frans Mofers, Wessel Slot, Dominique Sluijsmans, Howard, Spoelstra, Marjolein Terken, Hans van der Vleugel, Wim Westera.

\section{REFERENCES}

[Ger98] J. Gerrissen, R. Schuwer, Convergence of personal and organizational knowledge management in VirtualBusiness-based learning, presented at the Workshop on Hypertext Functionality HTF7, Helsinki (Finland), December 13, 1998.

[Lip97] J. Lipnack, J. Stamps, Virtual Teams: Reaching Across Space, Time, and Organizations With Technology, May 1997, John Wiley \& Sons, ISBN: 0471165530.

[OTEC98] D. Sluijsmans, J. Boon, D. de Haan, De alpharun van het virtueel bedrijf. Een evaluatie (in Dutch: The alpha-run of the Virtual Business. An evaluation), OTEC Report 98/W03, Open University of the Netherlands, 1998, pp. 1-66.

[Schu98] R. Schuwer, Een virtueel bedrijf als leeromgeving (in Dutch: A virtual company as a learning environment), in Informer, August 1998, pp. 16 - 18.

[Sloep99] P. Sloep, J. Gerrissen, D. Jansen, R. Schuwer, W. Van Petegem, Modes of Personal and Organizational Learning in VirtualBusinessTeams, ENABLE99 conference, Espoo (Finland), June 2-5, 1999.

[VPet99] W. Van Petegem, P. Sloep, J. Gerrissen, R. Schuwer, D. Janssen, VirtualBusinessTeams: Enabling Competence-Based Learning and Working in a Virtual Networked Enterprise, ENABLE99 conference, Espoo (Finland), June 2-5, 1999.

[Wes98a] W. Westera, P. Sloep, The Virtual Company: Toward A Self-Directed, CompetenceBased Learning Environment in Distance Education, in Educational Technology, Vol. 38 (1), 1998, pp. $32-38$.

[Wes98b] W. Westera, Competence learning in a virtual company: a paradigm shift in education, presented at Online Educa Berlin, 3 - 4 December 1998. 